\title{
Investigating students' mental models and knowledge construction of microscopic friction. I. Implications for curriculum design and development
}

\author{
Edgar D. Corpuz ${ }^{1}$ and N. Sanjay Rebello ${ }^{2}$ \\ ${ }^{1}$ Department of Physics and Geology, University of Texas-Pan American, 1201 West University Drive, \\ Edinburg, Texas 78539, USA \\ ${ }^{2}$ Department of Physics, 116 Cardwell Hall, Kansas State University, Manhattan, Kansas 66506-2601, USA
}

(Received 23 March 2011; published 26 July 2011)

\begin{abstract}
In this paper, we discuss the first phase of a multiphase study aimed at investigating the dynamics of students' knowledge construction in the context of unfamiliar physical phenomenon-microscopic friction. The first phase of this study involved the investigation of the variations in students' mental models of microscopic friction. Clinical interviews were conducted with 11 students enrolled in conceptual modern physics to elicit their ideas and generate themes of explanations. A phenomenographic approach of data analysis was employed to establish the variations in students' explanations. Results show that students' mental models of friction at the atomic level are dominated by their macroscopic experiences. Friction at the atomic level according to most students is due to mechanical interactions (interlocking or rubbing of atoms).
\end{abstract}

DOI: 10.1103/PhysRevSTPER.7.020102

PACS numbers: 01.40.Fk, 01.40.E-, 01.40.Ha

\section{INTRODUCTION}

Nanoscience is an emerging area of interest in science. In keeping up with this cutting-edge science, several educators [1-3] have developed curricular materials to help students at various educational levels understand nanoscience. However, these materials are often not integrated into a standard introductory physics course. There are several topics in the introductory physics curriculum where a discussion of phenomena at the nanoscale level may be integrated. Friction, for example, is one such topic. Students in introductory physics are often introduced to friction from a macroscopic perspective, but seldom are they introduced to the microscopic underpinnings of friction. An exception is the Matter and Interactions curriculum in which there is a detailed microscopic analysis of friction, with emphasis on the energetics of the phenomenon [4]. This study focuses on students' understanding of friction at the microscopic scale.

Although scientists, let alone students, struggle to understand microscopic friction, recent studies [5] indicate that the phenomena at the microscopic scale are fundamentally different than the familiar phenomena at the macroscopic scale. For instance, friction at the microscopic scale is mediated by electrostatic van der Waals interactions, while at the macroscopic scale it is merely described as a contact force between two surfaces in relative motion. This fundamental difference between the macroscopic and microscopic models of friction provides a useful context for

Published by the American Physical Society under the terms of the Creative Commons Attribution 3.0 License. Further distribution of this work must maintain attribution to the author(s) and the published article's title, journal citation, and DOI. exploring students' ideas and process of knowledge construction about the phenomenon.

Learning is explained by cognitive theories in terms of changes in mental processes and knowledge structures resulting from a learner's efforts to make sense of the world [6]. Learners may use what is often called a model, or more specifically a mental model, to understand unseen physical phenomena, such as those occurring at the microscopic scale. These models usually are structural and functional analogs of processes at the microscopic scale. Several models [7-10] have been proposed by scientists to explain the friction at the microscopic level. However, to date there have been no investigations of how students who learn about friction think about it at the microscopic level. The study described in this paper addressed the following research question: What are the variations in introductory college physics students' models of microscopic friction?

\section{THEORETICAL FRAMEWORK}

The study of students' mental models has been, and continues to be, an area of considerable interest of research in cognitive psychology and science education. Mental models according to Johnson-Laird [11] "are structural analogues of the world as perceived or conceptualized." Meanwhile, Gentner and Stevens [12] argue that "mental models are related to human knowledge of the world and of how it works, i.e., the way people understand some domain of knowledge." From Gilbert and Boulter's [13] perspective, a model is a "representation of a target which might be an object, event, process or system." Vosniadou [14] believes that "mental models refer to a special kind of mental representation, an analog representation, which individuals generate during cognitive functioning." 
Students' mental models are ways in which learners organize experiences to minimize the mental energy needed to make sense of the world around them [15-17]. Learners often test the adequacy of these models in light of new experiences, thereby constantly modifying and reorganizing them. Thus, at any point in a learner's development, these models may involve multiple representations, myriad rules, and procedures that the learner may not even know how to apply. Furthermore, these models may be nebulous, incomplete, or self-contradictory. During instruction, students build on and modify these mental models. Depending upon the complexity of the model, this change can be a long and difficult process for the learner. Greca and Moreira [18] define a mental model as an internal representation which acts out as a structural analogue of situations or processes. Its role is to account for the individual's reasoning when he or she tries to understand, predict, or explain the physical world.

In talking about mental models we cannot avoid the fact that they seem to be private in nature [19-21]. How then can we access somebody else's mental model? Gilbert and Boulter [13] suggest that we can rely on the expressed version of it, which they term expressed models. Expressed models are believed to represent selected aspects of phenomena and our mental models.

In this research, we subscribe to Greca and Moreira's idea that a mental model is an internal representation which acts out as a structural analogue of situations or processes which can be accessed through some expressed versions of it [13].

We are cognizant of the issue raised by Norman [20] that one should distinguish between an individual's mental models and the analysis that researchers carry out regarding these models. However, we could not disagree more with this issue of grasping or understanding students' mental models. In our research when referring to students' mental models we actually refer to our own model of students' understanding that is gleaned from students' expressed models.

Physicists typically construct models and associate attributes that are consistent with experimental evidence in order to communicate and explain physical phenomena. In the same manner, researchers construct a model about what or how a student might be thinking based on what they tell us in order to have a vocabulary or framework to describe what a student may be thinking and what difficulties he or she is experiencing while making sense of the situation. Based on our models of what students think about a particular phenomenon, instructors and curriculum designers can be in a better position to create interventions that will help students reorganize pieces of their knowledge and eventually improve their existing mental model so as to have a deeper and more coherent understanding of a given phenomenon.
TABLE I. The interviewees as per their major.

\begin{tabular}{lc}
\hline \hline Major & No. of students \\
\hline Mechanical Engineering & 4 \\
Secondary Education & 3 \\
Marketing & 1 \\
Computer Science & 1 \\
Microbiology & 1 \\
Undecided & 1 \\
Total & 11 \\
\hline \hline
\end{tabular}

\section{METHODOLOGY}

The goal of this phase of the research was to establish students' mental models of microscopic friction. In order to elicit students' mental models, two sessions of one-hour semistructured clinical interviews were conducted with individual students. The first interview session focused on establishing students' explanations of surfaces at different length scales, the cause of friction at the atomic level, and similarities and differences between kinetic and static friction. The second interview session, which occurred a day or two after the first session, focused on students' explanations of the lubricating mechanism of oil and variation of friction with surface roughness. Throughout these interviews students were requested to explain their ideas in words as well as through diagrams and sketches. The use of multiple representations of students' ideas often provided opportunities for further probing questions.

As a way of increasing the dependability [22] of the data collected, we asked students to summarize their explanations of the different model-eliciting activities before the end of the interview. The second interview session began by having students recall what they had done and said in the previous interview session. It is worth noting that all of the students interviewed were able to accurately recall what they did and said during the first session.

A total of 11 students enrolled in a conceptual modern physics course were interviewed. Table I shows the interviewees with their respective majors.

A list of preliminary questions was generated and pilottested with an expert to generate feedback. The preliminary questions were then revised based on the feedback generated. The revised interview protocol was subsequently pilot-tested with two students with backgrounds similar to our target interviewees. The final version of the interview protocol resulted from feedback received from the pilot interviews.

\section{RESULTS AND DISCUSSION}

A phenomenographic approach of analysis [23,24] was used in this study. As per this approach students' responses are grouped into naturally occurring categories based on 

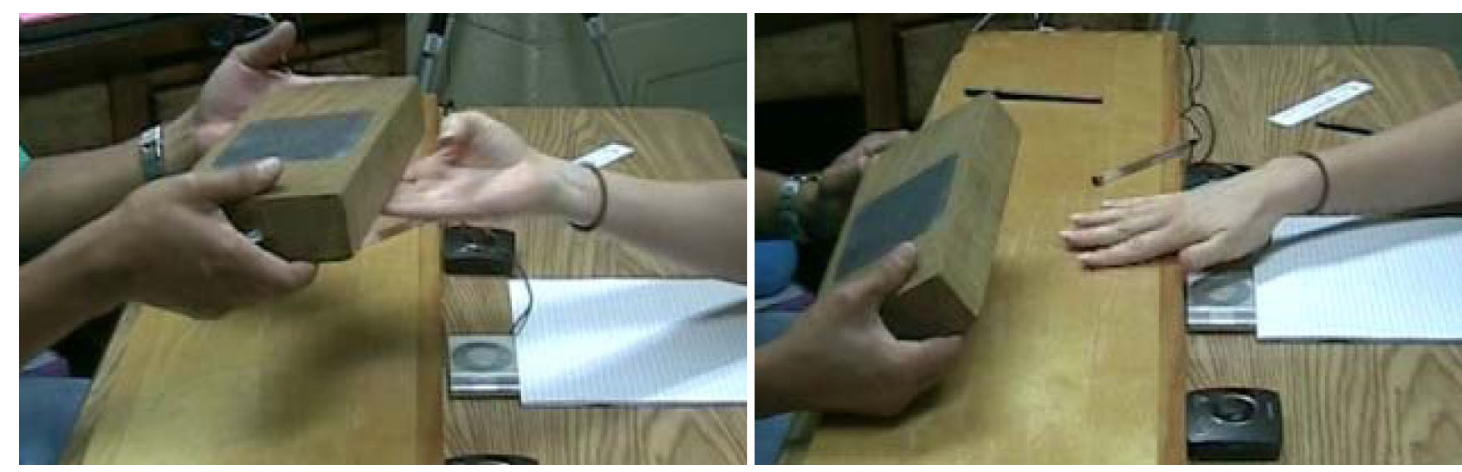

FIG. 1 (color online). Model-eliciting activity 1: Feeling of rough and smooth wooden surfaces.

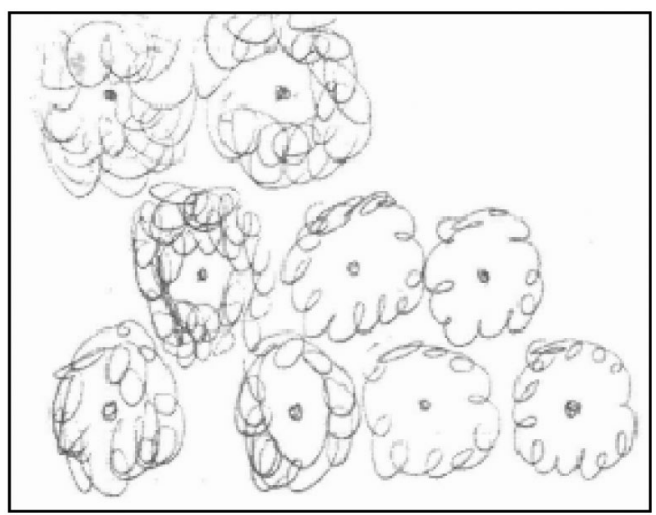

FIG. 2. Student model of an atom.

their quotes and excerpts. The interrater reliability of the categorization of at least $80 \%$ was established by having two other experts do the categorization independently. A second layer of thematic analysis combined the categories of responses in different contexts in the interview to generate themes.

Model-eliciting activities [25] were used to help the interviewer in probing the students' mental models of friction. Each model-eliciting activity provided a context in which to explore students' models by posing a list of questions. Below we present the different model-eliciting activities and the models elicited from students.

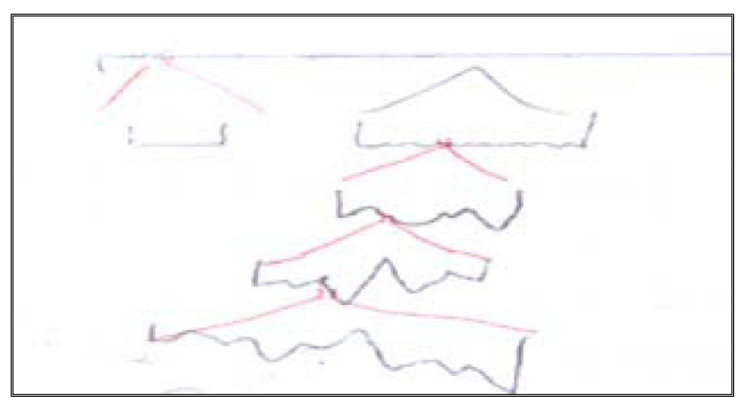

\section{A. Student models of surfaces at different length scales}

In this part of the interview students were asked to feel different surfaces (Fig. 1).

They were then asked to sketch what the surface would look like to them at the different length scales. Specifically, students were asked the following.

- Could you please sketch what a 10-cm length of the surface would look to you?

- If we consider 1/100 of your sketch, zoom in and magnify that part 100 times, what would that portion look to you? What would happen if you keep zooming in?

Below are sample quotes from the students interviewed.

- "If we keep zooming in, we will come to the atomic level where we will see individual atoms."

- "If we keep zooming in, we will come to the point where we see atoms which look like fuzzy bumps [student draws atom with an electron cloud, see Fig. 2 because of how the electrons are arranged."

- "The smaller you get ... umm ... what I'm saying is there is no magical way in which the atoms of the wood can arrange themselves into a completely flat surface. No matter how small you get there are always gonna be ... umm ... irregularities to it because it's made up of atoms .... I'm thinking that in actuality, they arrange more like this (draws atom arrangement similar to Fig. 2) so that you have, you know, these bumps here and indentation here."

An example of student sketches of how the surface would look at different length scales is shown in Fig. 3.

FIG. 3 (color online). Typical sketch by students of surfaces at different length scales. 


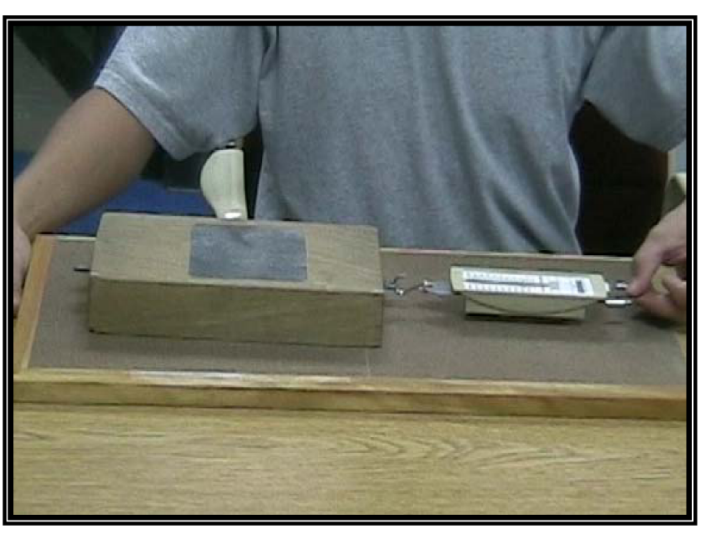

FIG. 4 (color online). Model-eliciting activity 2: A wooden block is dragged along a plank with half of it being covered by sandpaper.

In the sketch on the left, the student has shown how increased zooming in would reveal more asperities in the surface. When further pressed to zoom in to the atomic level, the student began to show atoms, i.e., circles arranged along zigzag paths, corresponding to the surface.

Most of the students interviewed eventually realized that zooming in would get them to the atomic level. However, they were unsure of the length scale at which that would occur. The examples as shown previously in Fig. 3 are typical sketches drawn by the interviewees.

\section{B. Students' models of microscopic friction}

To elicit students' ideas of friction they were asked to pull a wooden block across another wooden surface and then across a sandpaper surface (Fig. 4). The interviewees were then asked to explain their observations and explanations for their observations. Follow-up questions were asked to probe students' ideas of friction at the microscopic level. Examples of questions included are as follows.

- Could you please explain what is happening between the two surfaces as you try to move the block across the surfaces?

- So what causes friction between the surfaces?

- How does the force needed to start the block moving compare to the force needed to keep it moving across the top of the table once it has started moving?

- Now, please take time to think about how you might explain in your own words why the force needed to start the block moving is greater than the force needed to keep it moving.

The dragging of the wooden block across the sandpaper and wooden surface made students observe that they need a certain amount of force to move the object across the surfaces. In addition, they observed that they needed a greater amount of force to move the object across the sandpaper than in the wooden surface. The analysis of the transcripts generated from the interview showed three models that students used in explaining friction.

Table II shows the majors of the students and the models that students used. It can be seen from the table that the interlocking model was used by five students (two mechanical engineering majors, S1 and S2; one microbiology major, S8; one marketing major, S10; and one undecided major, S11). Meanwhile, five students (one mechanical engineering major, S4; three secondary education majors, S5, S6, and S7; and one computer science major, S9) used a rubbing-hitting-sliding model in explaining the friction between the block of wood and the surfaces onto which it was dragged. According to three students (one mechanical engineering, S3; one secondary education, S6; and one computer science, S9) friction is the breaking of bonds of the atoms. It should be noted that two students (S6 and S9) simultaneously used the rubbing-hitting-sliding model and breaking of bonds models in making sense of the friction between the surfaces.

Based on the data, the rubbing-hitting-sliding model seems to be the popular mental model among the secondary education major students. However, our data showed no other discernible pattern with regard to student models and their major. We feel that if one is interested in this issue, they would need to gather additional data to see patterns with respect to students' models in regard to their major. Since we were primarily interested in the variations of introductory students' models of friction, and not necessarily how the underlying patterns varied with respect to their educational background or majors, we did not pursue this issue further. In the proceeding section, we discuss the different models used in explaining friction and illustrative quotes from students.

\section{Intertwining-interlocking of atoms}

In this model, microscopic friction is the force needed to pull an atom over the bumps due to intertwining or

TABLE II. Models used in explaining friction as per student's major.

\begin{tabular}{|c|c|c|c|c|c|c|c|c|c|c|c|c|}
\hline & \multirow[b]{3}{*}{ Student code } & \multicolumn{11}{|c|}{ Student major } \\
\hline & & \multicolumn{4}{|c|}{$\begin{array}{l}\text { Mechanical } \\
\text { Engineering }\end{array}$} & \multicolumn{3}{|c|}{$\begin{array}{l}\text { Secondary } \\
\text { Education }\end{array}$} & \multirow{2}{*}{$\begin{array}{c}\text { Microbiology } \\
\text { S8 }\end{array}$} & \multirow{2}{*}{$\begin{array}{c}\text { Computer } \\
\text { Science } \\
\text { S9 }\end{array}$} & \multirow{2}{*}{$\begin{array}{l}\text { Marketing } \\
\text { S10 }\end{array}$} & \multirow{2}{*}{$\begin{array}{c}\text { Undecidec } \\
\text { S11 }\end{array}$} \\
\hline & & $\mathrm{S} 1$ & $\mathrm{~S} 2$ & $\mathrm{~S} 3$ & S4 & S5 & S6 & S7 & & & & \\
\hline \multirow{3}{*}{ Models } & Interlocking or intertwining & $\mathrm{x}$ & $\mathrm{x}$ & & & & & & $\mathrm{x}$ & & $\mathrm{x}$ & $\mathrm{x}$ \\
\hline & Rubbing or hitting & & & & $\mathrm{x}$ & $\mathrm{x}$ & $\mathrm{x}$ & $\mathrm{x}$ & & $\mathrm{x}$ & & \\
\hline & Breaking of bonds & & & $\mathrm{x}$ & & & $\mathrm{x}$ & & & $\mathrm{x}$ & & \\
\hline
\end{tabular}




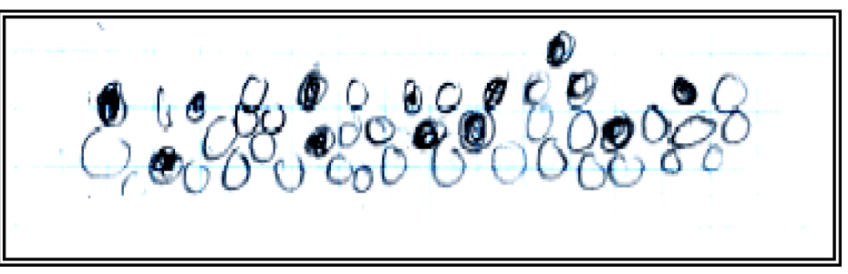

FIG. 5 (color online). The atoms of the wooden block (shaded) interlock with the atoms of the tabletop (not shaded).

interlocking of atoms. A pictorial representation of this model by students is shown in Fig. 5. The atoms of the surfaces are drawn to be interlocking or intertwining with each other.

Below are quotes from students that illustrate this model.

S1: "The maximum number of peaks touching and pressing each other causes greater amount of friction."

S2: "The atoms of the block prevent the motion because of the atoms are kind of intertwined with each other... when you set it [the block] on top, it kind of settles in like goes into a neutral energy state. When I try to move it I got to pull them out so there will be some friction because there will be some particles getting intertwined" (interviewee shows fingers of hand intertwining).

S8: "Well there is friction cause you kinda got the other surface of the wood pressing against. Also, it has a level of bumpiness even at the atomic scale ... and so these (points to the up and down arrangement of atoms) things kinds of pushing against each other. And so there's certain amount of force that you need to put into before you could overcome all of the little forces ... because of the bumps they have in them or in this scale (points to the sketch at the atomic scale) because of the way the kind of interaction between atoms, they're close to each other and they are pressing each other ... you need to overcome those."

S10: "Since we have irregularities in the two surfaces, they're gonna like interlocking and the friction is the force to overcome the interlocking of pieces (interviewee points to the atoms)."

It is obvious from the verbatim transcripts that the students who had this model think that there is friction between the wooden block and the other surface onto which it was dragged because of the interlocking or intertwining of atoms of the surfaces.

\section{Friction is the rubbing or sliding of atoms}

Figure 6 shows a pictorial representation of this model. The finite force that students observed when they dragged the wooden block across the sandpaper and wooden surface is explained by the rubbing or sliding of atoms past another.

Below are quotes from students that illustrate this model.

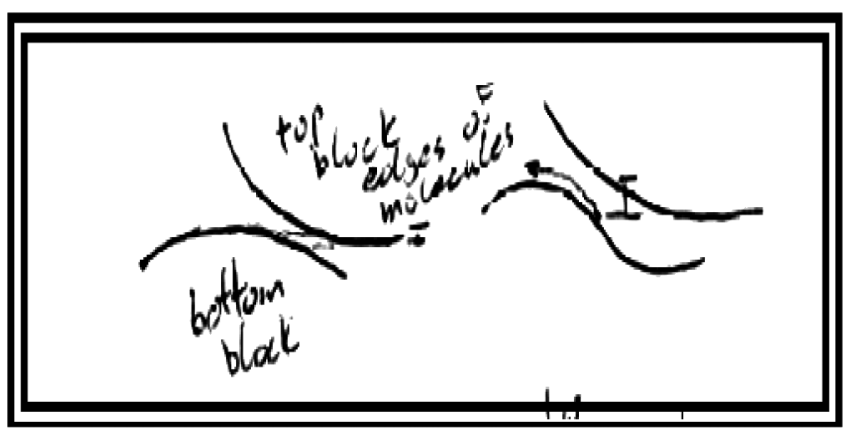

FIG. 6. The atoms of the wooden block rub against the atoms of the tabletop.

S4: "There is friction when one atom hits another atom that comes into its way."

S5: "Friction force is the interaction between the wood and the table .... It's the resistance between them. Atoms are sliding and move past one another ... they rub against one another producing friction."

S6: "They (atoms) are touching ... they are rubbing against each other. As I move it that way, these (points to the atoms) are rubbing against each other ... friction is produced by the different atoms rubbing against each other."

S7: “They (atoms) don't mesh together at all. They just sit on top of one another... they are touching but they don't interact anymore than just the physical contact ... one of them is moving and one of them isn't moving so they rub together."

S9: "I would think that it seems like when it is just sitting there, the surfaces are somehow interacting and making gone another almost rough .... The smoother it is the less energy to get over the bumps."

From the student quotes, it can be gleaned that these students think that there is friction between the wooden block and the other surface onto which it was dragged because at the atomic level we have the atoms rubbing or hitting each other.

\section{Bonding model}

Figure 7 shows a pictorial representation of this model by one of the students. According to three students

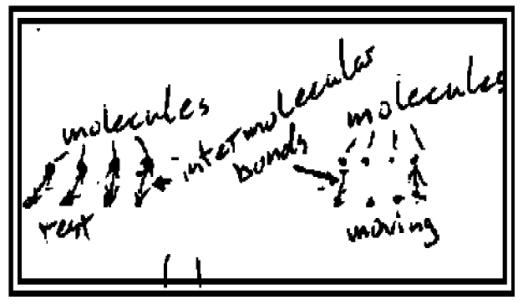

FIG. 7. Breaking of bonds causes friction. 
interviewed, friction is the force needed to break the bonds between atoms of surfaces that come into contact. Below are quotes from these students.

S3: "Friction comes from breaking the bond. The strength of friction depends on the strength of the bond."

S6: "Well I would say friction is the bond between the atoms. I don't know if that's electronic or ionic bonding."

S9: "So when it is just sitting, these two would form some sort of bond which makes them stick closer together ... you kinda have to overcome these little bonds enough to break them. When it has started moving, let's say they might not have enough time to form that (bond) and that (bond) one. So there's less number of bonds to be broken."

Based on the above student quotes, friction is produced by the breaking of bonds between the atoms of the surfaces that move past one another. It should be noted that two of the students (S6 and S9) simultaneously used the rubbing or hitting and breaking of bonds model.

\section{Why static friction is greater than kinetic friction}

There were four models that students used in explaining why static friction is greater than kinetic friction.

\section{Skimming over the top (five students).-}

Once the block started moving the atoms of the block just skim over the atoms of the other surface (Fig. 8). Four (S1, S2, S8, and S11) of the five students who used interlocking or intertwining of atoms in explaining friction used this model in explaining the difference between the friction when the object is just starting to move and when it was moving. Below are sample quotes from the students:

S1: "When it begins to slide it's just like running where the peaks bounce off each other so there's less peak hitting at the same time compared when the surfaces are stationary."

S2: "It already got some initial velocity .... We pulled off the atom. There's still gonna be resistance between the two at the molecular level ... but not as much because they are not settled in. When you're moving it they're gonna be not as intertwined."

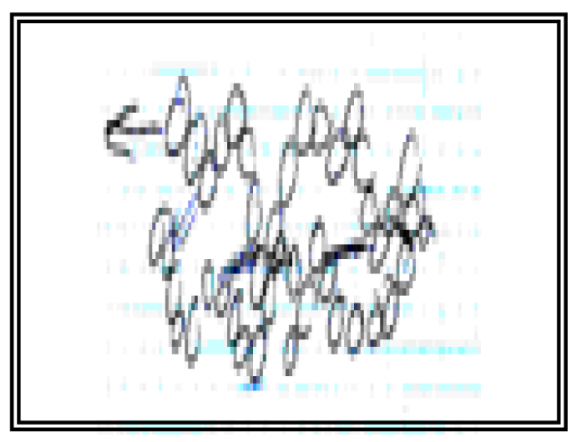

FIG. 8 (color online). The atoms of the wooden block skim over the top atoms of the table surface once it is in motion.
S11: "Once the block starts moving, the atoms don't go down the crevices. Atoms of the top surface bounce over the atoms of the lower surface. They don't have time to settle down into the grooves.... It doesn't allow this to dip down in. It just keeps moving along so it doesn't have time to find these deep grooves."

The analysis of the transcripts showed that five students (S1, S2, S4, S8, and S11) think that there is less friction when the wooden block is already moving because the atoms of the surfaces just skim over each other and no longer interlock or intertwine as much as when it was still at rest.

\section{Getting smoother (one student).-}

One of the students (S10) who earlier used the intertwining or interlocking model in explaining friction between the surfaces explained the difference between static and kinetic friction as follows.

"I would think that it seems like when it is just sitting there, the surfaces are somehow interacting and making one another almost more rough. The way this works basically is it is more rough when it wasn't moving than when it was."

Based on the above response we classified the student's model as "getting smoother." That is, the surfaces somehow got smoother once the surfaces started moving past each other.

\section{Changing downward force (one student).-}

In explaining the difference between static and kinetic friction, one of the students (S6) who previously explained friction using the rubbing-hitting model and breaking of bonds said the following.

"When it is at rest there's more pressure between the atoms ... when it starts moving, you have less force pulling down."

We represented this explanation as "changing downward force." In this model, when an object starts to move the downward force decreases.

\section{Fewer bonds (two students).-}

According to the two students (S3 and S9) who earlier used the bonding model in explaining friction, there are fewer bonds to break once the objects move relative to each other. According to one of the students:

"So when it's just sitting, these two would form some sort of bond which make them stick close together ... you kinda have to overcome these little bonds enough to break them. When it has started moving, let's say they might not have enough time to form that (bond) .... So there's less number of bonds to be broken."

In the "fewer bonds" model, less friction means that a fewer number of bonds needs to be broken. 
Follow-up and probing questions were also asked during the interview and these were quite different with each student. The probing questions in the clinical interviews were based on students' predictions and explanations during the different model-eliciting activities. In order to investigate the consistency of students' models, the interviewer asked "what if" questions. Example questions included the following.

- What if there is oil in between the surfaces?

- What if the surfaces are "atomically flat"?

- What if the activity was done on a place with no gravity?

In the proceeding section, we discuss students' explanation of friction if there is oil in between the surfaces.

\section{Lubricating mechanism of oil}

There were four models that students used in explaining friction when there is oil in between surfaces.

\section{Ball bearing model (five students).-}

According to five of the interviewees (S3, S5, S6, S8, and S9), oil atoms would act like ball bearings in reducing the friction between two surfaces. Below are sample quotes from the students.

S3: "I think it might be possible that they move past one another easier, but it could be that maybe oil molecules roll."

S5: "Friction comes from the rubbing of oil atoms with the wood atoms but the latter can move easier like a ball bearing. That's why there will be less friction."

S8: "Oil is a liquid and the atoms are more free to move around, and maybe roll .... In the solid, atoms can't be pushed away at all. They move a little bit but really they don't move as much as the molecules of the oil would."

It can be gleaned from the above quotes that the atoms of the oil will make two surfaces move past each other easier like a ball bearing.

\section{Floating model (five students).-}

The atoms of the oil according to five students (S1, S2, S4, S7, and S10) provide a floating barrier for the atoms of the wooden block. Below are sample quotes from the students.

S2: "Friction is less because oil is not a solid and it has less bumps and valleys. And interaction is basically oil atoms on each side ... so, the upper surface kinda floats."

S4: "Oil will help separate these bumps and valleys such that they don't have to interact with the full scale."

S10: "The atoms of the oil provide greater separation between the two surfaces so it reduces the interlocking."

In this model, less friction is attributed to the atoms of the oil providing a "floater" for the upper surface that slides past another.

\section{Reduction of bumps and valleys (two students).-}

Two students (S2 and S11) think that the atoms of the oil reduce the bumps and valleys thereby reducing resistance to movement. According to one of the students:

"Oil is not solid in a sense makes it a lot more flat to where nothing can stick out and go against stuff as it went by."

In this model, students think there's less friction if there is oil in between surfaces because the oil atoms seem to fill in the crevices, thus reducing the bumps and valleys in between.

\section{Weaker bonds (one student).-}

According to one of the students (S9), the oil in between the surfaces will weaken the bonds between the surfaces, thus there is a weaker bond to break, so there will be less friction.

“... they don't exhibit as much intermolecular bonds between each oil molecule than between oil and wood molecules so they can move past one another easier than the wood on wood."

Two of the students interviewed (S2 and S9) simultaneously used two of the above models in explaining the lubricating mechanism of oil. Student S2 used both the reduction of bumps and valleys model and the weaker bonds model. Meanwhile, student S9 used oil atoms as the ball bearing model and weaker bond model.

The two most dominant models that students used in explaining how oil reduces friction are the ball bearing and floating models. A majority of the students thought that oil atoms reduce friction in a way analogous to ball bearings or that they provided a floating barrier for the upper surface.

\section{E. Emergent themes}

Table III summarizes the different models that students used in explaining friction in the different contexts provided during the interview. Two overarching themes emerged from the second layer of analysis of the variations in the students' models of friction and lubrication: mechanical interactions and chemical interactions.

\section{Mechanical interactions.-}

The thematic analysis revealed the persistence of students' responses that friction is simply due to mechanical interactions of the atoms (interlocking or intertwining, rubbing or hitting, skimming through the top, getting smoother, atoms of oil acting as ball bearings, floating, and reduction of bumps and valleys).

The data suggest that students seemed to be consistent in the use of their models in the different contexts in the interviews. Students who started to explain friction using mechanical interactions of atoms continued to use such an explanation in the subsequent parts of the interview where 
TABLE III. Variations of student models in the different contexts in the interview.

\begin{tabular}{|c|c|c|c|c|c|c|c|c|c|c|c|}
\hline Student code & $\mathrm{S} 1$ & $\mathrm{~S} 2$ & S3 & S4 & S5 & S6 & S7 & S8 & S9 & $\mathrm{S} 10$ & $\mathrm{~S} 11$ \\
\hline \multicolumn{12}{|c|}{$\begin{array}{c}\text { Explaining friction at the microscopic scale } \\
\text { Mechanical interaction }\end{array}$} \\
\hline Interlocking or intertwining & $\mathrm{x}$ & $\mathrm{x}$ & & & & & & $\mathrm{x}$ & & $\mathrm{x}$ & $\mathrm{x}$ \\
\hline Rubbing or sliding & & & & $\mathrm{x}$ & $\mathrm{x}$ & $\mathrm{x}$ & $\mathrm{x}$ & & $\mathrm{x}$ & & \\
\hline \multicolumn{12}{|c|}{ Bonding model } \\
\hline Breaking of bonds & & & $\mathrm{x}$ & & & $\mathrm{x}$ & & & $\mathrm{x}$ & & \\
\hline \multicolumn{12}{|c|}{$\begin{array}{l}\text { Why kinetic is less than static friction }{ }^{\mathrm{a}} \\
\text { Mechanical interaction }\end{array}$} \\
\hline Skimming over the top & $\mathrm{x}$ & $\mathrm{x}$ & & $\mathrm{x}$ & & & & $\mathrm{x}$ & & & $\mathrm{x}$ \\
\hline Getting smoother & & & & & & & & & & $\mathrm{x}$ & \\
\hline \multicolumn{12}{|c|}{ Bonding model } \\
\hline Fewer bonds & & & $\mathrm{x}$ & & & & & & $\mathrm{x}$ & & \\
\hline \multicolumn{12}{|c|}{$\begin{array}{l}\text { Lubricating mechanism of oil } \\
\text { Mechanical interaction }\end{array}$} \\
\hline Oil as ball bearing & & & $\mathrm{x}$ & & $\mathrm{x}$ & $\mathrm{x}$ & & $\mathrm{x}$ & $\mathrm{x}$ & & \\
\hline Floating & $\mathrm{x}$ & $\mathrm{x}$ & & $\mathrm{x}$ & & & $\mathrm{x}$ & & & $\mathrm{x}$ & \\
\hline Reduction of bumps and valleys & & $\mathrm{x}$ & & & & & & & & & $\mathrm{x}$ \\
\hline \multicolumn{12}{|c|}{ Bonding model } \\
\hline Weaker bonds & & & & & & & & & $\mathrm{x}$ & & \\
\hline
\end{tabular}

${ }^{\text {a }}$ Three students did not give any explanation as to why kinetic friction is less than the static friction.

they were asked to explain the difference in force when an object is at rest and when it is moving and the lubricating mechanism of oil.

A majority of the interviewees (nine out of 11) consistently used mechanical interactions in explaining friction in the different contexts in the interview. When they were asked to explain what causes microscopic friction, most students alluded to the interlocking-intertwining or rubbing-hitting model. For these students friction is either the force needed to pull an atom over the bumps due to intertwining or interlocking of atoms or the force due to the rubbing or sliding of an atom past another atom. According to one of the students:

"... when I try to move it I got to pull them out so there will be some friction because there will be some particles getting intertwined."

When the five students with the interlocking model were asked what happens if the surfaces become atomically smooth, they said that friction persists because atoms still physically rub against each other.

"there will still be friction because there is still some contour in them (atoms)."

Similarly, when students were asked to explain why oil reduces friction, almost all of them likened the oil to ball bearings rolling on a surface.

"I think it might be possible that they move past one another easier, but it could be that maybe oil molecules roll."

Thus, for most students interviewed, there is friction between two surfaces at the microscopic level because of the mechanical interactions of the atoms.

\section{Chemical interaction.-}

The thematic analysis also revealed another theme. For three (S3, S6, S9) of the 11 students, microscopic friction is the force needed to break the bonds between the atoms of surfaces that come into contact. When these students were asked to explain why kinetic friction is less than static friction, two of these students thought that there were fewer bonds to break once the other surface is set in motion.

“... when it has started moving, let's say they might not have enough time to form that (bond) .... So there's less number of bonds to be broken."

Similarly, when asked to explain what happens when there is oil in between two surfaces, only one of the students consistently used the bonding model. According to this student friction is reduced because it's the weaker bond between oil and wood that needs to be broken instead of the bond between wood and wood.

\section{CONCLUSIONS}

Through clinical interviews with students we found that most of the students hold onto the idea that friction at the atomic level is simply due to mechanical interactions. This is evident from the models used by students in explaining the friction between the wooden block and the surfaces onto which it was dragged, why static friction is greater than kinetic friction as well as the lubricating mechanism of oil. When students were asked to sketch how the smoothest surface would look at the atomic level, they often drew atoms lining up. When asked if there was still friction when two such surfaces come into contact and 
move past one another, students interviewed would typically say, "There will still be friction because there is still some contour in them (atoms)." All of these responses are consistent with the notion that friction is due to mechanical interactions between atoms. Only one of the students seemed to consistently use the bonding model in explaining microscopic friction. Thus, for most students, what they view as mechanical interactions of the macroscopic world are also applicable to explain friction at the microscopic scale.

The aforementioned findings motivated us to do further research on how students can be helped to improve their present models of friction. In this context, we conducted teaching interviews with introductory physics students with the aim of studying the dynamics of their model construction as they interacted with scaffolding activities. During these teaching interviews students were presented with scaffolding activities geared toward facilitating model construction and reconstruction among students in order to help them construct more scientific models of microscopic friction. The second part of this paper will address the dynamics of students' knowledge construction as they interact with different scaffolding activities geared towards refining their ideas about microscopic friction.

\section{ACKNOWLEDGMENTS}

This paper is based in part upon work supported by the National Science Foundation under Grant No. REC0133621.
[1] P. Schank and A. Wise, Introducing High School Students to Nanoscale Science, Forum on Education of The American Physical Society, Summer 2006 Newsletter.

[2] A. Wise, P. Schank, T. Stanford, and G. Horsma, Do you know what you're putting on your body? Studying the science behind new nanoparticulate sunscreens. Sci. Teach. 76, 6 (2009).

[3] http://www.discovernano.northwestern.edu/getinvolved/ teachers.

[4] R.W. Chabay and B. A. Sherwood, Matter and Interactions (Wiley, New York, 2010), 3rd ed.

[5] M. O. Robbins and J. Ringlein, Understanding and illustrating the atomic origins of friction, Am. J. Phys. 72, 884 (2004).

[6] P. D. Eggen and D. P. Kauchak, Educational Psychology: Windows on Classrooms (Prentice Hall, Upper Saddle River, NJ, 2004).

[7] C. E. Swartz and T. Miner, Teaching Introductory Physics: A Resource Book (AIP, Woodbury, NY, 1997).

[8] F. P. Bowden and D. Tabor, Friction and Lubrication of Solids (Oxford University Press, Northamptonshire, England, 1950).

[9] A. R. Burns and J.E. Houston, Friction and Molecular Deformation in the Tensile Regime, Phys. Rev. Lett. 82, 1181 (1999).

[10] J. Krim, Surface science and the atomic-scale origins of friction: What once was old is new again, Surf. Sci. 500, 741 (2002).

[11] P. N. Johnson-Laird, Mental Models: Towards a Cognitive Science of Language, Inference and Consciousness (Harvard University Press, Cambridge, MA, 1983).

[12] D. Gentner and A. L. Stevens, Mental Models (Lawrence Erlbaum, Hillsdale, NJ, 1983).

[13] J. K. Gilbert and C. J. Boulter in International Handbook of Science Education, edited by K. Tobin and B. Frazer (Kluwer, Dordrecht, 1998), pp. 52-66.
[14] S. Vosniadou, Capturing and modeling the process of conceptual change, Learn. Instr. 4, 45 (1994).

[15] R. Driver and B. Bell, Students' thinking and the learning of science: A constructivist view, Sch. Sci. Rev. 67, 443 (1986).

[16] E. Glasersfeld, Cognition, construction of knowledge and teaching, Synthese 80, 121 (1989).

[17] E.F. Redish, in Theoretical Framework for Physics Education Research: Modeling Student Thinking, Proceedings of the International School of Physics "Enrico Fermi," Course CLVI (IOS, Amsterdam, 2004).

[18] I. M. Greca and M. A. Moreira, Mental, physical, and mathematical models in the teaching and learning of physics, Sci. Educ. 86, 106 (2002).

[19] C. Franco and D. Colinvaux, in Developing Models in Science Education edited by J. K. Gilbert and C. J. Boulter (Kluwer Academic, Dordrecht, 2000), pp. 93-118.

[20] D. A. Norman, in Mental Models edited by D. A. Gentner and A.L. Stevens (Lawrence Erlbaum, Hillsdale, NJ, 1983).

[21] B. C. Buckley and C. J. Boulter, in Developing Models in Science Education edited by J. K. Gilbert and C. J. Boulter (Kluwer Academic, Dordrecht, 2000), pp. 119-135.

[22] E. G. Guba and Y.S. Lincoln, Fourth Generation Evaluation (Sage, Newbury Park, CA, 1989).

[23] F. Marton, Phenomenography-A research approach to investigating different understanding of reality, J. Thought 21, 29 (1986).

[24] L. Svennson, Theoretical foundations of phenomenography, High. Educ. Res. Dev. 12, 59 (1997).

[25] R. Lesh and A.E. Kelly, in Multitiered Teaching Experiments in Handbook of Research Design in Mathematics and Science Education, edited by R. Lesh and A. E. Kelly (Lawrence Erlbaum Assoc., Mahwah, NJ, 2000), pp. 197-230. 